\title{
Digital Anthropology in Work Life Rhythm
}

\author{
Sriram S, G. Rajini
}

\begin{abstract}
Intelligent technology has touched and improved upon almost every aspect of employee life cycle, Human resource is one of the areas, which has greatly benefited. Transformation of work mainly question the way we work, where we work, how we work and mainly care about the environment and surroundings in which we work. The main goal is to support the organizations to break out their traditional way of work and further move towards to an environment, which brings more pleasing atmosphere, flexible, empowering and communicative.

Machine learning, algorithms and artificial intelligence are the latest technology buzzing around the HR professional minds. Artificial intelligence designed to take decisions based on data fed into the programs. The key difference between rhythm and balance is of choice vs adjustment. The choice is made easier, only with the help of priority, quick decision-making, time and communication. To maintain the above scenario digitalisation plays a vital role. In this paper, we suggest the artificial assistants focus on improving the rhythm of individual
\end{abstract}

\section{Keywords: Artificial Intelligence, Rhythm, Priority, Choice}

\section{INTRODUCTION}

Work and home life are no longer a separate entity. The merging of both have been made possible by the arrival of digital technologies. Transformation of work mainly focused on information technology in human resource management to develop more creative and fastest ways of handling people, which mainly works on people integration. When we start focus on the time and priority, we required the support of machine learning to act immediately according to situations, which result in avoiding the miscommunication between the individuals. Our main aim is to achieve and enjoy in both work and personal life.

\section{OBJECTIVE}

Managing rhythm in everyday life becomes easier with the support of machine learning and latest technology. This also reduce your time; avoid error and get you remind to complete the task effectively.

\section{WORK LIFE RHYTHM}

work-life rhythm is a more realistic description for the workers in 21st-century. Prior to working on your work-life balance, it is essential to sit down, prioritize what holds real importance for you, and then work your way backward from there. Finding a way to push through the busy seasons and learn your own and your company's rhythms may be the difference maker in the growth of your productivity and

\footnotetext{
Revised Manuscript Received on September 10, 2019.

Sriram. S, PhD Research Scholar (Part-Time), School of Management Studies, VISTAS, Tamil Nadu, India.

(Email:marirs_85@yahoo.com/)

G. Rajini, Professor and Head-MBA (Integrated), School of Management Studies, VISTAS, Tamil Nadu, India.

(Email: rajini.sms@velsuniv.ac.in/)
} your life.

What do you want from life? Everything is a choice, this is life greatest truth and its hardest lesson-Mathew Kelley(1999).When you're at work, really engage. And when you're at home, really BE at home

"I love this concept of work life rhythm, it's a more accurate representation of how your day and week plays out," says Jennifer Folsom, chief of corporate development at Summit Consulting. "I believe that sometimes work wins, sometimes life wins, but it can't always be one or the other. There will be some days and weeks where you will be spending a ton of time with kid stuff and other busy periods at work.

Mainly work life rhythm speaks on how you plan your daily routine work, when sometimes if plan A does not work choose the priority \& time and focus continuously to achieve it and then proceed to your regular work.

\section{ARTIFICIAL INTELLIGENCE (AI)}

AI is an area of computer science that emphasizes the creation of intelligent machines that work and react like humans.

It is estimated by McKinsey that automation could replace $45 \%$ of activities currently carried out by humans, but only $5 \%$ of jobs could be completely automated by technology.

\section{AI IN EVERYDAY LIFE:}

\section{EMAIL COMMUNICATIONS:}

- $\quad$ Like email filters, it prevents $99 \%$ of spam from getting into your inbox

- Smart Replies in gmail/linked in with the click of button

- Nudging reminders in gmail:Determine the email which required response

- Web searches: Google algorithms

SOCIAL MEDIA:

- $\quad$ Linked in

- Facebook Proactive detection

- Pinterest

- Chatbots

OTHER AI:

- Product recommendations

- Music recommendations

- Mobile banking

- Alerts on fraud prevention

- Maps and Directions 


\section{Digital Anthropology in Work Life Rhythm}

\section{EXAMPLES:}

SIRI :

Spin-off from a project originally developed by the SRI International Artificial Intelligence Center. Its speech recognition engine was advanced machine learning technologies to function

\section{ALEXA:}

It controls several smart devices using itself as a home automation system. It is capable of voice interaction, music playback, making to-do lists, setting alarms, streaming podcasts, playing audiobooks, and providing weather, traffic, sports, and other real-time information

\section{AI IN WORK PLACE MEANS WORKPLACE OF THE} FUTURE:

- $\mathrm{AI}$ in transforming the hiring process

- $\mathrm{AI}$ in eliminating repetitive administrative tasks

- Transforming internal communication and support

- Transforming marketing, sales and customer service

- Improving on boarding and training

- Transforming business data and analytics

- Fighting fraud and transforming security

- Enabling problem solving and innovation

- Transforming productivity

\section{DIGITAL /SOCIAL REVOLUTION}

Communication landscape is more different than it was for past 20 years ago and these changes automation, social message, remote work etc, these are all drastically changing

To survive, humans need to rely on both their feelings of achievement and enjoyment. This brings equilibrium in their lives. While achievements are fine in establishing a sense of accomplishment, minus enjoyment, it means little. This encompasses achieving the balance across work, family, friends and yourself

We are living through a fundamental transformation in the way we work. Automation and 'thinking machines' are replacing human tasks and jobs, and changing the skills that organisations are looking for in thier people

\section{METHODOLOGY AND STATISTICAL REPORT \& RESULTS}

Model survey on the work and life place digitalisation was conducted with 57 working people of different age group and across sex

Below mentioned the graph (Image:1)shows the age group and sex who have responded for the survey
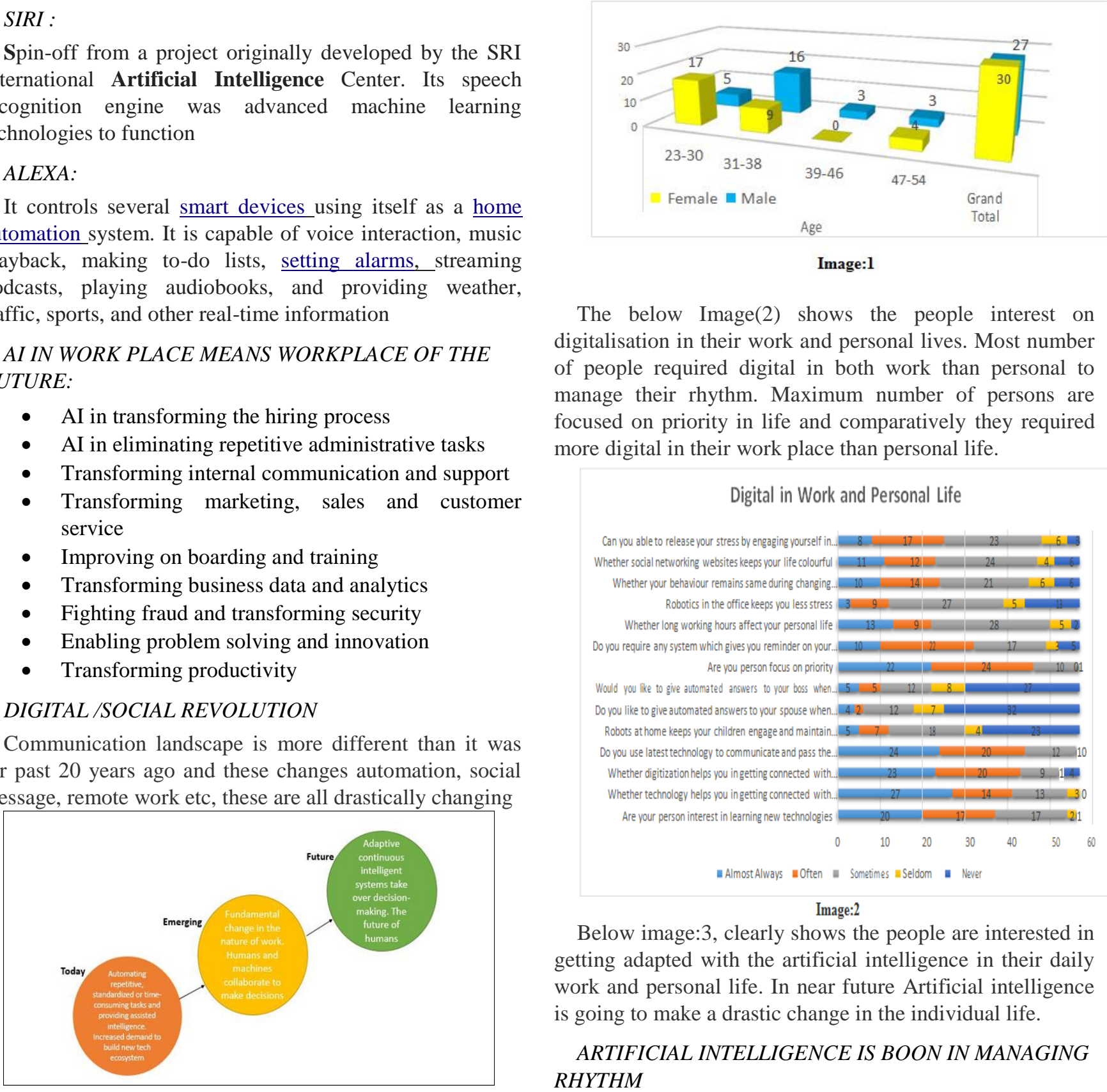

Image: 1

The below Image(2) shows the people interest on digitalisation in their work and personal lives. Most number of people required digital in both work than personal to manage their rhythm. Maximum number of persons are focused on priority in life and comparatively they required more digital in their work place than personal life.

Digital in Work and Personal Life

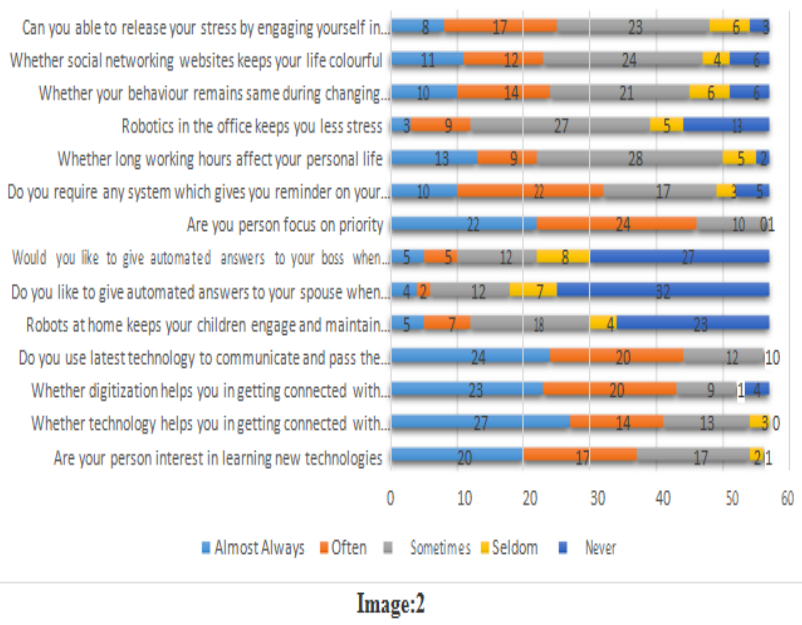

Below image:3, clearly shows the people are interested in getting adapted with the artificial intelligence in their daily work and personal life. In near future Artificial intelligence is going to make a drastic change in the individual life.

ARTIFICIAL INTELLIGENCE IS BOON IN MANAGING RHYTHM

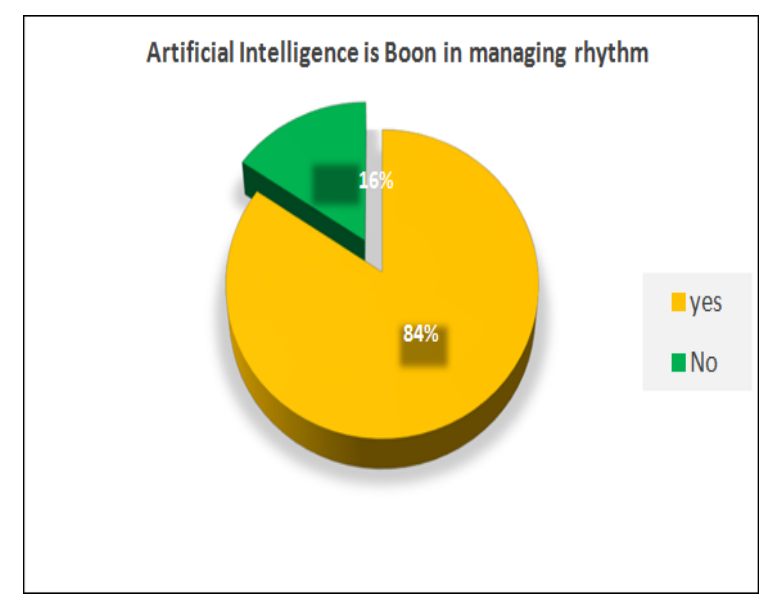

Image:3

Published By: 


\section{CONS OF AI IN WORK LIFE RHYTHM:}

More we communicate through digital network; the easier is to lose the human element that's so vital for our daily life. Distracting notifications.

- Increased room for misinterpretation.

- Making employees feel isolated and unfulfilled in their work.

- Increased risk of workplace contention as people say things digitally they would not say in person.

- Lack of privacy in communications with clients, colleagues, and managers.

- Virtual barriers that inhibit relationship building.Information overload leading to overwhelmed employees who miss important information.

\section{CONCLUSION}

When you are working hard, realize this is your season to do so and make plans for time to recharge, renew, and spend quality time with the people you love. It can be very stressful to cramp in too many tasks in a seven-hour workday. This is detrimental to personal relationships, health, and overall happiness. Similarly, monotonous work days too can leave you feeling unfulfilled and disengaged. This leaves a lot of scope for automation to help in creating a work-life rhythm and give your priorities the attention that they deserve. When the automation gets transformed to our life, we get Quality of work place and Quality of life

\section{REFERENCES}

1 Four ways, AI is improving work life balance, Angela White Jun 142019

2 Rhonda Bradley, 2018: AI in every day life

3 Mathew Kelley,(2011):Getting Beyond the Work-Life Balance Myth to Personal and Professional Satisfaction

4 Jessica Greene, 2019:AI Transforming the workplace

5 Geetha R \& Bhanu sree reddy D,2018: volume 9, Issue 7, Recruitment through artificial intelligence.

6 Martin FR, Jan 10,2019: Employers are now using artificial intelligence

7 Vijay K Sharma, 2019:Uses of Artificial Intelligence in daily life

8 Theodora, May 23, 2019:When AI becomes part of our daily life

9 Severin Lemaignan, Mathieu Warnier, E.Akin Sisbot, Rachid Alami,2017: Artificial cognition for social human-robot interaction: An implementation

10 Hellstrom A,Condelius A,Willman A, Fagerstorm C(2015): Rhythm of unit in pace of life

11 Jason E Taylor,Apr 27, 2017:The Rhytym of life and work 